Cite this: RSC Advances, 2013, 3, 2595

Received 13th November 2012 Accepted 7th December 2012

DOI: $10.1039 / c 2 r a 22874 b$

www.rsc.org/advances

\title{
Microwave-assisted coating of carbon nanostructures with titanium dioxide for the catalytic dehydration of D-xylose into furfural†
}

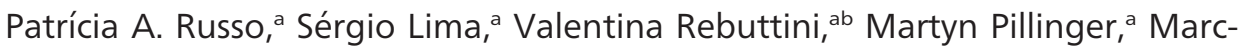 \\ Georg Willinger, ${ }^{c}$ Nicola Pinna*ab and Anabela A. Valente*a
}

\begin{abstract}
Titanium dioxide was selectively grown on reduced graphene oxide $\left(\mathrm{TiO}_{2} / \mathrm{RGO}\right)$ and carbon black $\left(\mathrm{TiO}_{2} /\right.$ $\mathrm{CB}$ ) by a microwave-assisted synthesis in benzyl alcohol to produce nanocomposite catalysts (consisting of 8-9 $\mathrm{nm}$ anatase nanoparticles dispersed on the carbon surface) with interesting properties for the production of furfural from renewable carbohydrate biomass. The materials efficiently catalyze the aqueous-phase dehydration of xylose into furfural at $170{ }^{\circ} \mathrm{C}$ with high furfural yields (67-69\%) at high conversions (95-97\%). The catalytic performance was not significantly affected by the type of carbon support, suggesting that cheap amorphous carbons can be used to support the titania nanoparticles. Additionally, the catalysts were found to be stable under hydrothermal conditions and outstandingly stable towards coke formation in comparison to other solid acid catalysts reported in the literature. Both composites were reused after a simple wash and drying procedure without any detectable loss of catalytic activity in consecutive batch runs.
\end{abstract}

\section{Introduction}

The use of biomass for the production of fuels, energy and chemicals is being regarded as a sustainable alternative to the use of petroleum feedstocks. ${ }^{1-3}$ Contrary to the declining petroleum resources, carbohydrate-rich biomass is renewable, abundant and relatively inexpensive, as its sources include (non-edible) agricultural and plant wastes or forest industry by-products. ${ }^{1,4}$ Carbohydrate biomass can be converted into valuable products such as furfural (Fur), which is a common industrial solvent and an intermediate compound for the production of fine chemicals, resins/plastics and biofuel components. $^{1,2,5}$ Furfural is formed by the acid-catalyzed dehydration of xylose (the most abundant pentose present in the hemicellulose component of lignocellulosic biomass), and it is produced industrially through processes that commonly use mineral acids as catalysts $\left(e . g . \mathrm{H}_{2} \mathrm{SO}_{4}\right)$ and lead to typical yields of $c a .50 \% .^{1,4}$ The expected continuous increase in the demand for furfural, ${ }^{6}$ however, requires the development of more efficient, economical and environmentally friendly routes to ensure the sustainability of furfural-related indus-

\footnotetext{
${ }^{a}$ Department of Chemistry, CICECO, University of Aveiro, Campus de Universitário de Santiago, 3810-193, Aveiro, Portugal.E-mail: atav@ua.pt

${ }^{b}$ Humboldt-Universität zu Berlin, Institut für Chemie, Brook-Taylor-Straße 2, 12489 Berlin, Germany.E-mail: nicola.pinna@hu-berlin.de

${ }^{c}$ Fritz Haber Institute of the Max Planck Society, Department of Inorganic Chemistry,

Faradayweg 4-6, 14195 Berlin, Germany

† Electronic supplementary information (ESI) available See DOI: 10.1039/

c2ra22874b
}

tries. Therefore, different approaches have been investigated in order to improve the production processes. It was found that the reaction yield can be raised by removing the furfural from the aqueous phase immediately after its formation with, for instance, supercritical $\mathrm{CO}_{2}{ }^{7}$ or an organic extracting solvent. ${ }^{8,9,11,12}$ This prevents furfural from being consumed in undesired secondary reactions typically taking place in the aqueous phase. In fact, very recently Huber and co-workers proposed a new process for the production of furfural using a two zone biphasic reactor (containing an extracting solvent), estimated to consume $67-80 \%$ less energy than the current industrial process. ${ }^{4}$

The replacement of the homogeneous catalysts by stable, recyclable, active and selective solid catalysts would also have economic and environmental benefits on the large-scale production of furfural, by minimizing corrosion problems and amounts of neutralization waste, and facilitating the recovery and reutilization of the catalyst. For this reason, several solid acid catalysts have been tested in the dehydration of xylose into furfural, including zeolites, ${ }^{8,10,11,13}$ sulfated metal oxides, ${ }^{14-16}$ organic polymers, ${ }^{17,18}$ supported heteropolyacids, ${ }^{19}$ or exfoliated metal oxide nanosheets. ${ }^{20}$ While some very promising results have been obtained, these studies also point out how challenging it remains to find catalysts with high activity and selectivity, that are structurally and chemically stable during repeated utilizations and stable towards coke formation. 
Carbon materials have attractive properties for catalytic applications such as a fairly high thermal stability, high water tolerance and low cost. ${ }^{21,22}$ Indeed, carbon-supported acid catalysts have shown interesting performances in the conversion of carbohydrates to furanic aldehydes. ${ }^{22,23}$ In particular, sulfonated graphene oxide was found to dehydrate xylose in water at $200{ }^{\circ} \mathrm{C}$ with an average furfural yield of $61 \%$ (compared to $44 \%$ for the uncatalyzed system) for repeated catalytic cycles. ${ }^{22}$

The anatase phase of titanium dioxide is also capable of catalyzing the dehydration of carbohydrates, ${ }^{7,24-27}$ although it is clear from the few works reported in the literature that the performance of titania catalysts depends strongly on its structural and morphological properties. ${ }^{25-27}$ For example, the use of nanostructured $\mathrm{TiO}_{2}$ was found to significantly favor the formation of 5-hydroxymethylfurfural from glucose and fructose ${ }^{26,27}$ with the high catalytic activity being attributed, among other factors, to the morphology of the nanoparticles. ${ }^{26}$ $\mathrm{TiO}_{2}$ has also been tested in the catalytic aqueous phase conversion of lignocellulosic biomass to furfural (Fur yields were less than 15\%), ${ }^{24,25}$ and the activity was found to be strongly affected by the preparation method of the catalyst. ${ }^{25}$ Other solids containing titanium, namely $\mathrm{SO}_{4}{ }^{2-} / \mathrm{TiO}_{2}{ }^{14}$ and $\mathrm{H}_{2} \mathrm{Ti}_{3} \mathrm{O}_{7}{ }^{20}$ nanosheets, have also been tested in the dehydration of xylose. $\mathrm{SO}_{4}{ }^{2-} / \mathrm{TiO}_{2}$ led to a modest furfural yield of $17 \%$ after $48 \mathrm{~h}$ of reaction at $100{ }^{\circ} \mathrm{C}$ (poorer results were reported when $\mathrm{TiO}_{2}$ was replaced with $\mathrm{Al}_{2} \mathrm{O}_{3}, \mathrm{SiO}_{2}, \mathrm{ZrO}_{2}, \mathrm{Fe}_{2} \mathrm{O}_{3}$ or $\left.\mathrm{Nb}_{2} \mathrm{O}_{5}\right) \cdot{ }^{14} \mathrm{H}_{2} \mathrm{Ti}_{3} \mathrm{O}_{7}$ nanosheets led to $\mathrm{ca}$. $40 \%$ furfural yield at $160{ }^{\circ} \mathrm{C} / 1 \mathrm{~h} .{ }^{20}$ However, this catalyst was obtained by exfoliation of the corresponding layered metal oxide using quite laborious and time-consuming procedures. Furthermore, the catalyst was deactivated by coking and required reactivation by thermal treatment at $350{ }^{\circ} \mathrm{C}$. Low stability of solid catalysts towards deactivation by coke is highly undesired, as it brings costly consequences for process design and operation. ${ }^{28}$

Here, we report the synthesis and characterization of new $\mathrm{TiO}_{2} /$ carbon catalysts that efficiently convert xylose into furfural. $\mathrm{TiO}_{2} /$ reduced graphene oxide $\left(\mathrm{TiO}_{2} / \mathrm{RGO}\right)$ and $\mathrm{TiO}_{2} /$ carbon black $\left(\mathrm{TiO}_{2} / \mathrm{CB}\right)$ nanocomposites were synthesized by a microwave-assisted "benzyl alcohol route", a synthetic approach proven to be very versatile in terms of allowing the synthesis of a high variety of metal oxides, hybrid materials and composites, and also to lead to nanomaterials with improved performances in several applications. ${ }^{29-36}$ The obtained materials were capable of converting xylose to furfural with yields of $67-69 \%$, and were found to be hydrothermally stable and resistant against deactivation by coke formation, which allowed their reuse in consecutive catalytic runs, without the need of applying harsh thermal or chemical treatments.

\section{Experimental}

\subsection{Synthesis of the nanocomposites}

Graphene oxide and carbon black (Vulcan XC72R, Cabot) were the carbon materials used to support the titanium dioxide nanoparticles. GO was prepared from graphite powder $(<20$ $\mu \mathrm{m}$, synthetic, Aldrich) by a modified Hummers method ${ }^{37}$ previously reported. ${ }^{34}$ Prior to the synthesis of the nanocomposites, the carbon black $(1 \mathrm{~g})$ was oxidized by refluxing in $5 \mathrm{M}$ $\mathrm{HNO}_{3}$ at $80{ }^{\circ} \mathrm{C}$ for $4 \mathrm{~h}$ and then thoroughly washed with water.

The deposition of the $\mathrm{TiO}_{2}$ nanoparticles on the carbon surface was done by the microwave-assisted "benzyl alcohol route". Suitable amounts of carbon and metal oxide precursor were added to the reaction mixture in order to obtain composites containing approximately 50 wt $\%$ of $\mathrm{TiO}_{2}$. Briefly, $0.05 \mathrm{~g}$ of the carbon material, $5 \mathrm{~mL}$ of benzyl alcohol $(\geqslant 99.9 \%$, Aldrich) and $0.18 \mathrm{~g}$ of titanium(IV) isopropoxide (99.999\%, Aldrich) were placed into a $10 \mathrm{~mL}$ microwave vial under argon. The mixture was sonicated until the carbon was dispersed and then heated in a CEM Discover SP microwave at $240{ }^{\circ} \mathrm{C}$ for $10 \mathrm{~min}$. The resulting solid was separated by centrifugation, washed with ethanol and dried at $65{ }^{\circ} \mathrm{C}$. GO and $\mathrm{CB}$ treated in benzyl alcohol at $240{ }^{\circ} \mathrm{C}$ for $10 \mathrm{~min}$ without the addition of the metal oxide precursor were also prepared.

\subsection{Characterization}

The carbon content of the samples was determined with a TruSpec 630 elemental analyzer, while the titanium amount was assessed by ICP-AES analysis (experimental range of error of 5\%), using an ICP Jobin Yvon Activa $\mathrm{M}$ analyzer. Nitrogen adsorption isotherms at $-196{ }^{\circ} \mathrm{C}$ were measured on a Quantachrome Quadrasorb SI. Prior to the measurements the samples were outgassed at $150{ }^{\circ} \mathrm{C}$ overnight. X-Ray powder diffraction patterns were obtained with a PANalytical X'Pert diffractometer at $45 \mathrm{kV}$ and $40 \mathrm{~mA}$, using $\mathrm{Cu}-\mathrm{K} \alpha$ radiation $(\lambda=$ $0.1541 \mathrm{~nm})$. Raman measurements were performed at $532 \mathrm{~nm}$ with a Jobin Yvon T64000 spectrometer. FTIR spectra were recorded on a Bruker Tensor 27 spectrometer using $\mathrm{KBr}$ pellets of the solid. Characterization of the final reaction solutions was done by ${ }^{1} \mathrm{H}\left(300 \mathrm{MHz}, \mathrm{CDCl}_{3}, \mathrm{TMS}\right)$ and ${ }^{13} \mathrm{C}(75 \mathrm{MHz}$, $\mathrm{CDCl}_{3}$, TMS) NMR measurements performed on a Bruker AVANCE 300 spectrometer. Thermogravimetric (TGA) and differential scanning calorimetry (DSC) analyses were performed from room temperature to $550{ }^{\circ} \mathrm{C}$, with a heating rate of $5{ }^{\circ} \mathrm{C} \mathrm{min}^{-1}$, under nitrogen atmosphere, on a Shimadzu TGA-50 and Shimadzu DSC-50, respectively. Scanning electron microscopy (SEM) images were recorded with a Hitachi SU-70 microscope operating at 10 or $30 \mathrm{kV}$. Transmission electron microscopy (TEM) images were obtained on a Hitachi H9000 microscope at an accelerating voltage of $300 \mathrm{kV}$. High resolution TEM (HRTEM) images were acquired on a FEI Titan equipped with a $\mathrm{C}_{\mathrm{s}}$ corrector and operated at $300 \mathrm{kV}$.

\subsection{Catalytic tests}

Batch catalytic experiments were performed under nitrogen atmosphere in closed tubular glass micro-reactors $(10 \mathrm{~mL}$ capacity) equipped with a PTFE-coated magnetic stirring bar. In a typical procedure, the reactor was loaded with D-xylose ( $0.67 \mathrm{M}$ in the aqueous phase), powdered catalyst (catalyst bulk density of $10 \mathrm{~g}_{\text {cat }} \mathrm{L}^{-1}$ ) and a solvent mixture (denoted $\mathrm{W}-\mathrm{T}$ ) comprising $\mathrm{H}_{2} \mathrm{O}$ and toluene used in a $0.3: 0.7$ (v/v) ratio. The reaction mixtures were heated at $170{ }^{\circ} \mathrm{C}$ in a Anton Paar Monowave 300 microwave oven with magnetic stirring at 1000 rpm. After each batch run, the catalyst was separated from the 
reaction mixture by centrifugation, thoroughly washed with deionized water and methanol, and finally dried at $55{ }^{\circ} \mathrm{C}$ overnight.

The products present in the aqueous phase were analyzed using a Knauer K-1001 HPLC pump and a PL Hi-Plex H 300 $\mathrm{mm}$ x $7.7 \mathrm{~mm}$ (i.d.) ion exchange column (Polymer Laboratories Ltd., UK), coupled to a Knauer 2300 differential refractive index detector (for xylose) and a Knauer $2600 \mathrm{UV}$ detector (280 nm, for Fur). The mobile phase was $0.001 \mathrm{M}$ $\mathrm{H}_{2} \mathrm{SO}_{4}$. The analytical conditions were the following: flow rate $0.6 \mathrm{~mL} \mathrm{~min}{ }^{-1}$, column temperature $65{ }^{\circ} \mathrm{C}$. The Fur present in the organic phase was quantified using a Gilson 306 HPLC pump and a Spherisorb ODS S10 C18 column, coupled to a Gilson $118 \mathrm{UV} / \mathrm{Vis}$ detector $(280 \mathrm{~nm})$. The mobile phase consisted of $37 \% \mathrm{v} / \mathrm{v}$ methanol and $63 \% \mathrm{v} / \mathrm{v} \mathrm{H}_{2} \mathrm{O}$ (flow rate 0.5 $\mathrm{mL} \min ^{-1}$ ). Authentic samples of D-xylose and Fur were used as standards and calibration curves were used for quantification. For each reaction time, at least two replicates of an individual experiment were made; the reported results are the average values. The Fur yield (\%) and the conversion of xylose $(\%)$ at reaction time $t$ were calculated using the formulae: Fur yield $=[($ moles of Fur formed at time $t) /($ initial moles of xylose $)]$ $\times 100$; conversion $=[$ (initial moles of xylose $)-($ moles of xylose at time $t)] /($ initial moles of xylose $)] \times 100$.

\section{Results and discussion}

\subsection{Characterization of the catalysts}

The use of microwave heating allowed the fabrication of $\mathrm{TiO}_{2} /$ carbon nanocomposites by the "benzyl alcohol route" in just $10 \mathrm{~min}$ and with high yields ( $c a .98 \%$ ). Table 1 summarizes some of the chemical and textural properties of the asprepared materials. Titanium and carbon elemental analyses showed that the materials are composed of approximately 43 $\mathrm{wt} \%\left(\mathrm{TiO}_{2} / \mathrm{RGO}\right)$ and $44 \mathrm{wt} \%\left(\mathrm{TiO}_{2} / \mathrm{CB}\right)$ titanium dioxide and ca. $50 \mathrm{wt} \%$ carbon, which agrees well with the nominal chemical compositions.

The X-ray diffractograms of the $\mathrm{TiO}_{2} / \mathrm{RGO}$ and $\mathrm{TiO}_{2} / \mathrm{CB}$ composites (Fig. 1) exhibit the typical reflections of the tetragonal anatase structure of titanium dioxide (JCPDS file no. 21-1272). The characteristic broad (002) reflection of the carbon supports centered around $25^{\circ}(2 \theta)$ is not noticeable on the patterns of the composites due to the much higher intensity of the metal oxide reflections and its overlapping with the (101) reflection of $\mathrm{TiO}_{2}$. By applying the Scherrer

Table 1 Chemical and textural properties of the as-prepared $\mathrm{TiO}_{2} /$ carbon nanocomposites

\begin{tabular}{lllcl}
\hline Sample & $\mathrm{C} / \mathrm{wt}^{a}{ }^{a}$ & $\mathrm{TiO}_{2} / \mathrm{wt}^{b}{ }^{b}$ & $A_{\mathrm{BET}} / \mathrm{m}^{2} \mathrm{~g}^{-1 c}$ & $V_{p 0.95} / \mathrm{cm}^{3} \mathrm{~g}^{-1 d}$ \\
\hline $\mathrm{TiO}_{2} / \mathrm{RGO}$ & 47 & 42.9 & 86 & 0.16 \\
$\mathrm{TiO}_{2} / \mathrm{CB}$ & 52 & 44.4 & 106 & 0.20
\end{tabular}

${ }^{a}$ carbon weight percentage determined by CHNS analysis. ${ }^{b} \mathrm{TiO}_{2}$ weight percentage determined by ICP-AES. ${ }^{c}$ specific surface area calculated by using the BET method. ${ }^{d}$ pore volume calculated from the amount adsorbed at $p / p^{\circ}=0.95$.

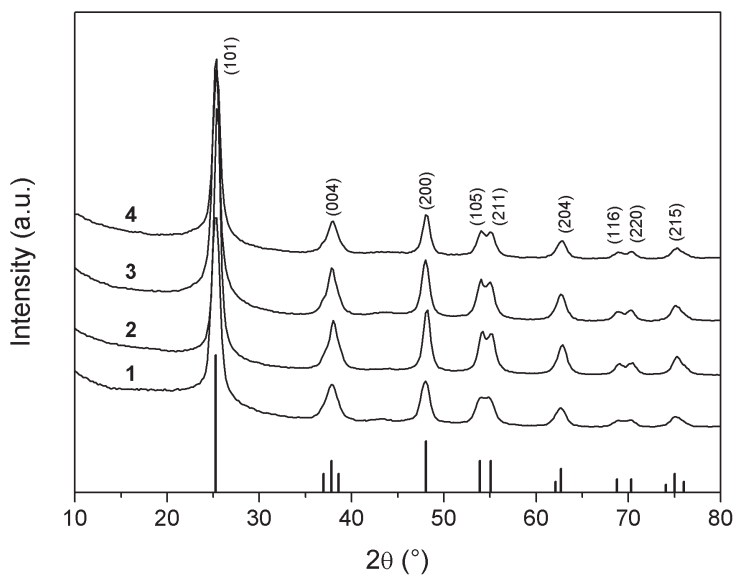

Fig. 1 X-Ray powder diffraction patterns of $\mathrm{TiO}_{2} / \mathrm{RGO}$ (1), $\mathrm{TiO}_{2} / \mathrm{RGO}$ after catalytic reaction (2), $\mathrm{TiO}_{2} / \mathrm{CB}(3)$ and $\mathrm{TiO}_{2} / \mathrm{CB}$ after catalytic reaction (4) (standard diffraction peaks of anatase (JCPSD file no. 21-1272) are shown as vertical bars).

equation to the (200) diffraction peak of the metal oxide, the average size of the titanium dioxide crystallites were estimated to be 8 and $9 \mathrm{~nm}$ for $\mathrm{TiO}_{2} / \mathrm{RGO}$ and $\mathrm{TiO}_{2} / \mathrm{CB}$, respectively.

The Raman data confirms the presence of anatase in the composites (Fig. 2a). Anatase has six Raman active vibrational modes below $700 \mathrm{~cm}^{-1}\left(\mathrm{~A}_{1 \mathrm{~g}}+2 \mathrm{~B}_{1 \mathrm{~g}}+3 \mathrm{E}_{\mathrm{g}}\right){ }_{.}{ }^{38}$ The spectra of the pristine $\mathrm{TiO}_{2} /$ carbon materials show at least five peaks that are in close agreement with those reported in the literature for the anatase phase of titanium dioxide, ${ }^{38}$ specifically at $\sim 153 \mathrm{~cm}^{-1}$ $\left(\mathrm{E}_{\mathrm{g}}\right), 203 \mathrm{~cm}^{-1}\left(\mathrm{E}_{\mathrm{g}}\right), 391 \mathrm{~cm}^{-1}\left(\mathrm{~B}_{1 \mathrm{~g}}\right), 506 \mathrm{~cm}^{-1}\left(\mathrm{~A}_{1 \mathrm{~g}}\right)$ and 637 $\mathrm{cm}^{-1}\left(E_{g}\right)$. The $B_{1 g}$ vibration mode, which occurs at $516 \mathrm{~cm}^{-1}$ for bulk anatase, probably overlaps with the $A_{1 g}$ peak. The spectra of the uncoated carbon materials treated in benzyl alcohol (Fig. 2b) feature the characteristic D and G bands at 1342 and $1585 \mathrm{~cm}^{-1}$ for $\mathrm{CB}$, and 1344 and $1587 \mathrm{~cm}^{-1}$ for RGO, respectively. Highly ordered graphite presents an intense $\mathrm{G}$ band at $1580 \mathrm{~cm}^{-1}$ corresponding to the vibration of $\mathrm{sp}^{2}$ hybridized carbon atoms of the lattice and a weak D band at $1350 \mathrm{~cm}^{-1}$ associated with carbon atoms located at the edges of graphite planes and at defects. Increase of the structural disorder in graphite leads to broader $\mathrm{G}$ and $\mathrm{D}$ bands, blue shifts in the $\mathrm{G}$ band position and to relatively intense $\mathrm{D}$ bands compared to the G bands (high $I_{\mathrm{D}} / I_{\mathrm{G}}$ ratios). ${ }^{39}$ Indeed, both $\mathrm{CB}$ and RGO have high $I_{\mathrm{D}} / I_{\mathrm{G}}$ ratios (1.4 and 1.3 , respectively) that reflect the high degree of structural disorder and/or the presence of a high amount of defects (oxygen-containing groups). The $I_{\mathrm{D}} / I_{\mathrm{G}}$ ratios decrease to 1.2 for the composites, which suggests that the quantity of defects diminished, possibly as a result of the $\mathrm{TiO}_{2}$ nanoparticles growth on the defective regions of the carbon surfaces.

SEM (Fig. S1 in the ESI') and TEM (Fig. 3) images of the materials reveal that large portions of the carbon surfaces are coated with metal oxide nanoparticles. Moreover, no significant amount of free nanoparticles could be seen by the TEM study of the samples, indicating that the $\mathrm{TiO}_{2}$ selectively grow on the carbon. This preferential growth of the nanoparticles on the carbon surface can be attributed to the relatively high 

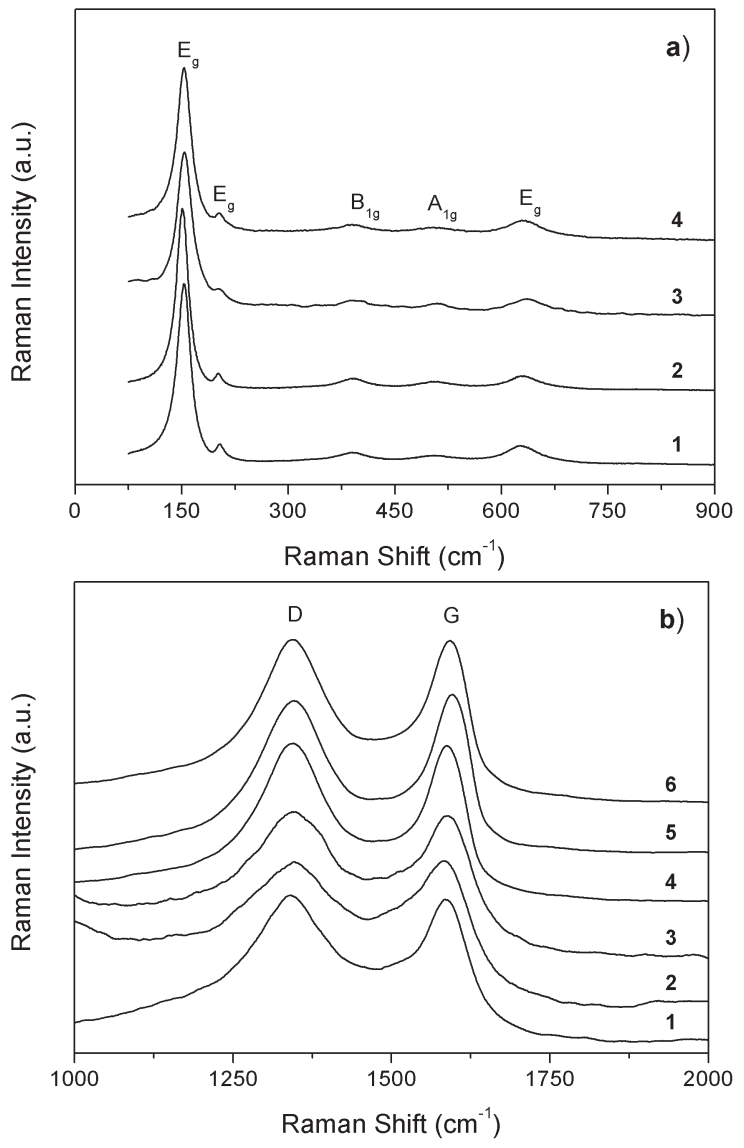

Fig. 2 (a) Raman spectra of the nanocomposites: $\mathrm{TiO}_{2} / \mathrm{CB}(1), \mathrm{TiO}_{2} / \mathrm{CB}$ after catalytic reaction (2), $\mathrm{TiO}_{2} / \mathrm{RGO}$ (3) and $\mathrm{TiO}_{2} / \mathrm{RGO}$ after catalytic reaction (4); (b) Raman spectra showing the $\mathrm{D}$ and $\mathrm{G}$ bands of $\mathrm{CB}(1), \mathrm{TiO}_{2} / \mathrm{CB}(2), \mathrm{TiO}_{2} / \mathrm{CB}$ after catalytic reaction (3), $\mathrm{RGO}(4), \mathrm{TiO}_{2} / \mathrm{RGO}(5)$ and $\mathrm{TiO}_{2} / \mathrm{RGO}$ after catalytic reaction (6).

microwave absorption capacity of the carbon materials in relation to the solvent, which favors the nucleation of the metal oxide on the carbon surfaces. ${ }^{33}$ The mean size of the $\mathrm{TiO}_{2}$ nanoparticles estimated by analysis of the TEM images is 8.0 and $8.7 \mathrm{~nm}$ for $\mathrm{TiO}_{2} / \mathrm{RGO}$ and $\mathrm{TiO}_{2} / \mathrm{CB}$, respectively, which is consistent with the results obtained from the XRD data. When imaged in high resolution (HRTEM), the RGO-supported $\mathrm{TiO}_{2}$ nanoparticles show well defined lattice fringes. Fig. 4a shows an edge of a RGO sheet covered by a dense monolayer of $\mathrm{TiO}_{2}$ nanoparticles. The power spectrum (PS) of the whole HRTEM image (Fig. 4b) shows sharp spots due to the $8 \mathrm{~nm} \mathrm{TiO}{ }_{2}$ nanoparticles. All the spots can be safely attributed to the anatase structure; some of the most intense reflections are assigned on the figure. The HRTEM image of a single $8 \mathrm{~nm}$ particle (Fig. 4c) show lattice fringes characteristic of a single anatase nanocrystal imaged under the [101] zone axis, as also demonstrated by its PS (Fig. 4d). Similar behavior is also observed for the $\mathrm{TiO}_{2}$ nanoparticles supported on carbon black ( $c f$. Fig. S2 and S3 in the ESI†).

The textural properties of the nanocomposites were investigated by $\mathrm{N}_{2}$ adsorption at $-196{ }^{\circ} \mathrm{C}$ (Fig. 5, Table 1). The $\mathrm{TiO}_{2} /$ RGO solid is mesoporous, as indicated by the high $p / p^{\circ}$

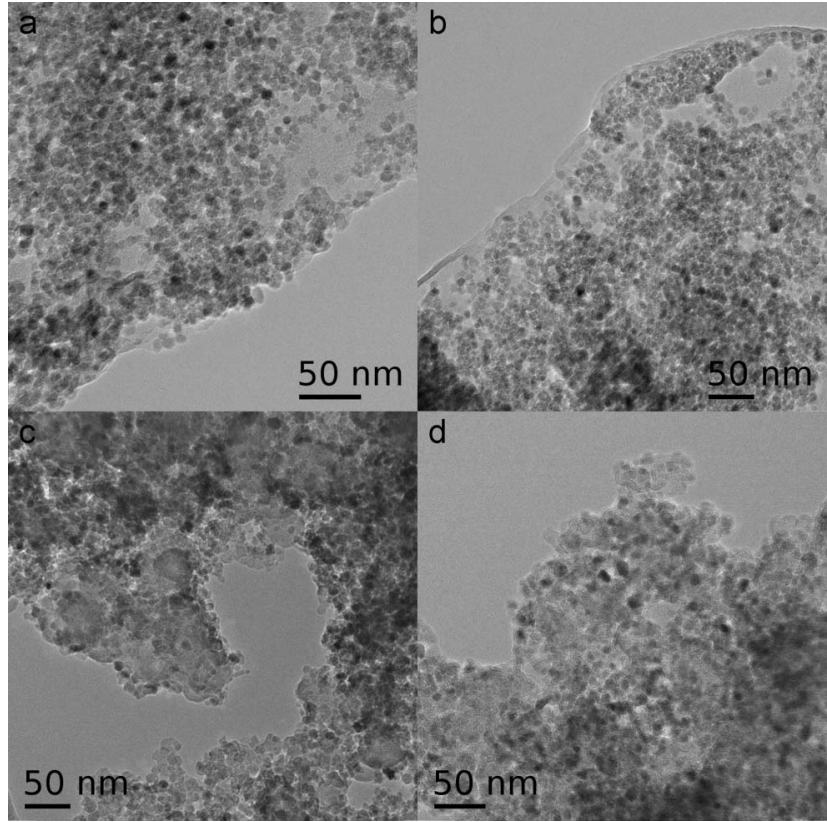

Fig. $3 \mathrm{TEM}$ images of $\mathrm{TiO}_{2} / \mathrm{RGO}(\mathrm{a}), \mathrm{TiO}_{2} / \mathrm{RGO}$ after catalytic reaction (b), $\mathrm{TiO}_{2} /$ $\mathrm{CB}$ (c) and $\mathrm{TiO}_{2} / \mathrm{CB}$ after catalytic reaction (d).

hysteresis cycle observed on the corresponding isotherm, and has a BET specific surface area $\left(A_{\mathrm{BET}}\right)$ of $86 \mathrm{~m}^{2} \mathrm{~g}^{-1}$. The $\mathrm{TiO}_{2} /$ $\mathrm{CB}$ material has only slightly higher $A_{\mathrm{BET}}$ and no measurable micropore volume $\left(V_{\mathrm{mp}}\right)$, in contrast with the uncoated carbon black $\left(A_{\mathrm{BET}}=253 \mathrm{~m}^{2} \mathrm{~g}^{-1}\right.$ and $V_{\mathrm{mp}}=0.045 \mathrm{~cm}^{3} \mathrm{~g}^{-1} ; V_{\mathrm{mp}}$ was determined by the $\alpha_{\mathrm{s}}$ method using standard data for $\mathrm{N}_{2}$ adsorption on non-porous carbon). ${ }^{40}$ This suggests that the $\mathrm{TiO}_{2}$ nanoparticles deposited on the surface of the carbon black particles completely block the micropores, which is consistent with the TEM images showing the carbon surface almost fully coated by metal oxide nanoparticles.

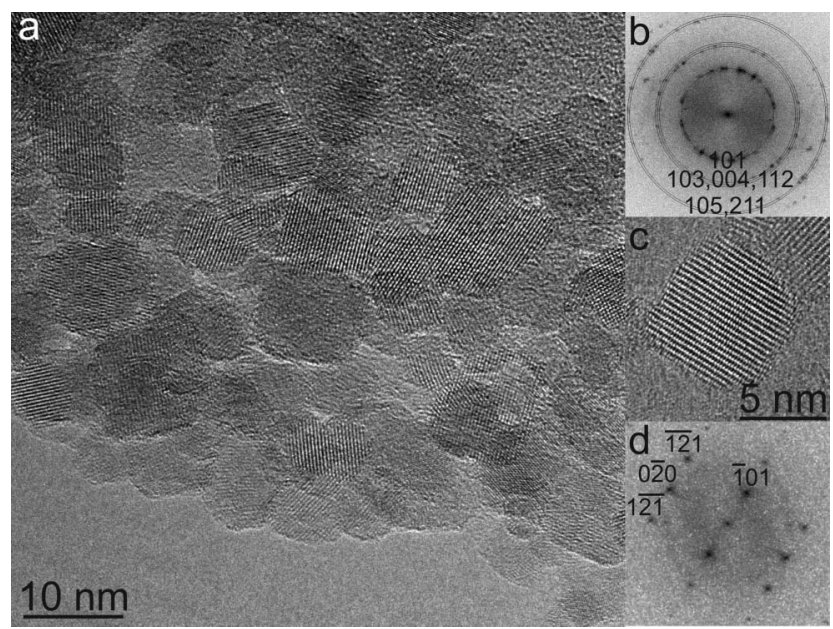

Fig. 4 HRTEM image of $\mathrm{TiO}_{2} / \mathrm{RGO}$ (a) and its power spectrum (PS) (b), HRTEM

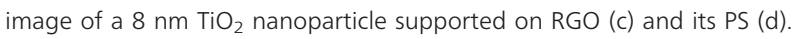




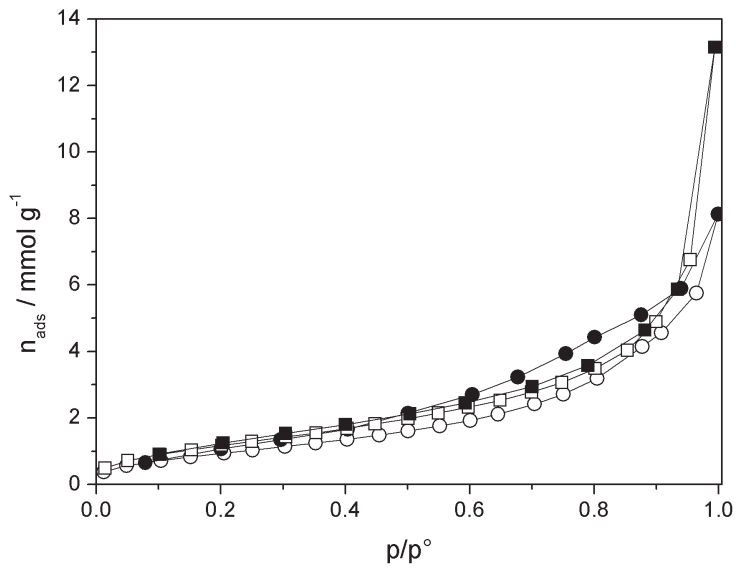

Fig. 5 Nitrogen sorption isotherms measured at $-196{ }^{\circ} \mathrm{C}$ of the as-prepared $\mathrm{TiO}_{2} / \mathrm{CB}(\square)$ and $\mathrm{TiO}_{2} / \mathrm{RGO}(O)$ composites (open symbols: adsorption; closed symbols: desorption).

The type of functional groups present on the as-prepared materials was evaluated by FTIR spectroscopy. All the spectra shown in Fig. 6 (of the $\mathrm{TiO}_{2} /$ carbon nanocomposites and uncoated carbon supports) show several bands assigned to oxygen-containing functionalities. The spectrum of RGO exhibits a band at $1570 \mathrm{~cm}^{-1}$ associated with the vibration of $\mathrm{C}=\mathrm{C}$ bonds of the graphene sheets, bands at $1735 \mathrm{~cm}^{-1}$ and $1205 \mathrm{~cm}^{-1}$ resulting from carbonyl $(\mathrm{C}=\mathrm{O})$ and epoxy $(\mathrm{C}-\mathrm{O})$ groups, respectively, and a band at $1060 \mathrm{~cm}^{-1}$ attributed to the stretching of $\mathrm{C}-\mathrm{O}$ bonds of $\mathrm{COOH}$ groups. ${ }^{41}$ In addition to this latter band, the spectrum of CB also shows a band at 1634 $\mathrm{cm}^{-1}$ that indicates the presence of quinones and a band at $1375 \mathrm{~cm}^{-1}$ attributed to phenolic hydroxyl groups. ${ }^{42}$ The spectra of the $\mathrm{TiO}_{2}$ /carbon nanocomposites exhibit the bands referred above, arising from the corresponding carbon material, and additionally a broad band between 400 and $700 \mathrm{~cm}^{-1}$, attributed to the vibrations of Ti-O bonds. ${ }^{43}$

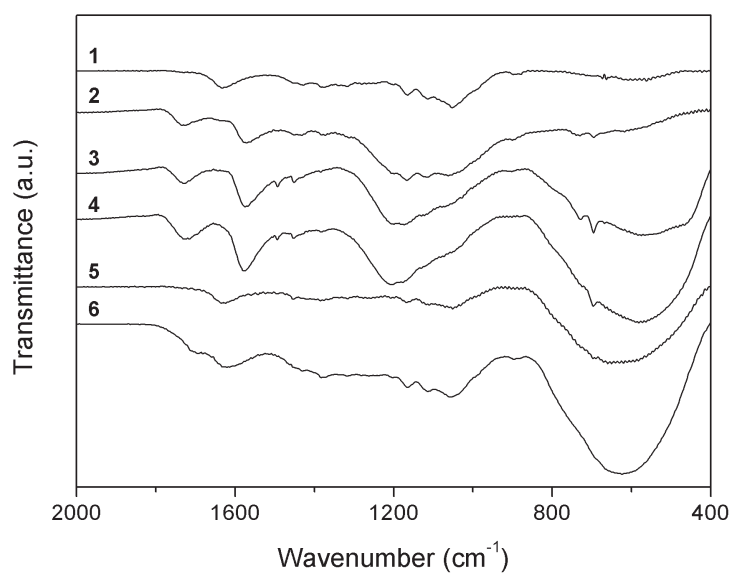

Fig. 6 FTIR spectra of carbon black (1) and graphene oxide (2) treated in benzyl alcohol (RGO), $\mathrm{TiO}_{2} / \mathrm{RGO}$ (3), $\mathrm{TiO}_{2} / \mathrm{RGO}$ after catalytic reaction (4), $\mathrm{TiO}_{2} / \mathrm{CB}$ (5) and $\mathrm{TiO}_{2} / \mathrm{CB}$ after catalytic reaction (6).
An interesting particularity of the microwave-assisted synthesis of the $\mathrm{TiO}_{2} /$ carbon composites is that the carbon itself seems to play an important role in the formation of the metal oxide nanoparticles under the experimental conditions used. In fact, the metal oxide is not formed when the reaction is performed without the carbon, whereas the composite materials can be produced by microwave irradiation of the reaction mixture for only $10 \mathrm{~min}$. In order to obtain further information about the reactions occurring in the presence and absence of the carbons, the final reaction solutions (recovered by centrifugation and filtration) were analyzed by ${ }^{13} \mathrm{C}$ and ${ }^{1} \mathrm{H}$ NMR spectroscopy. The final reaction mixtures of the $\mathrm{TiO}_{2} /$ carbon syntheses contained benzyl ether as the second major component (after benzyl alcohol, BA) and also isopropanol (Fig. 7b and Fig. S4b, ESI $\dagger$ ). The presence of benzyl ether indicates that the formation mechanism of the $\mathrm{TiO}_{2}$ nanoparticles on the carbon surface involves a condensation reaction with elimination of an ether (ether elimination), in agreement with the literature. ${ }^{44,45}$ Moreover, the formation of isopropanol suggests that prior to the condensation reaction most of the titanium precursor reacts with BA to give titanium benzyl alkoxide with the consequent co-formation of isopropanol. A similar two-step mechanism has been proposed for the solvothermal synthesis of $\mathrm{HfO}_{2}$ from the reaction of

a)

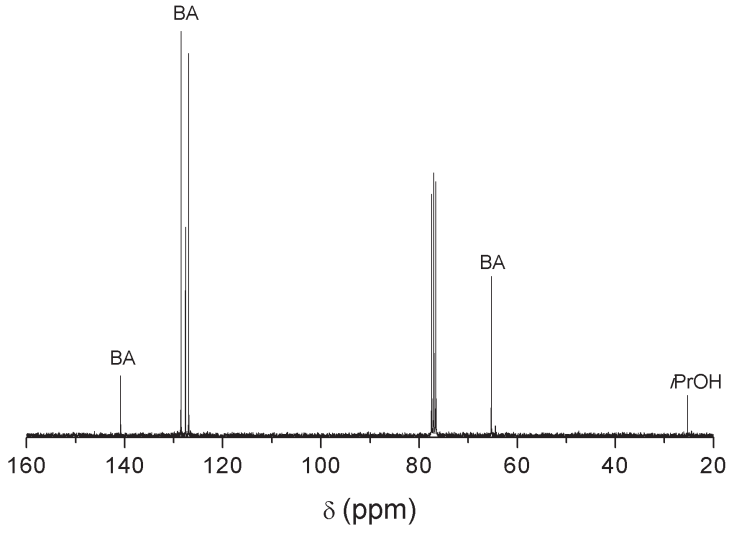

b)

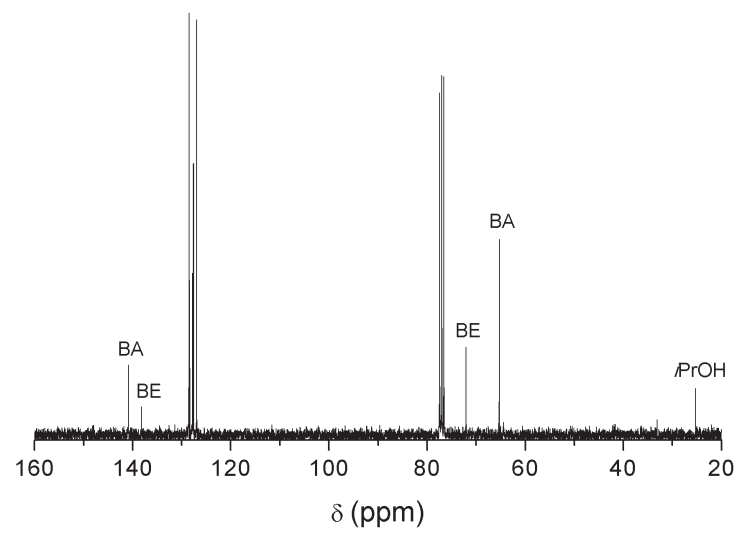

Fig. $7{ }^{13} \mathrm{C}$ NMR spectra of the reaction solution of the microwave-assisted synthesis of $\mathrm{TiO}_{2}$ (a) and $\mathrm{TiO}_{2}$ /carbon nanocomposites in benzyl alcohol (b) (iPrOH- isopropanol; BA-benzyl alcohol; BE-benzyl ether). 
hafnium ethoxide with benzyl alcohol. ${ }^{31}$ In the absence of the carbon material only isopropanol (in addition to BA) is detected in the final solution (Fig. 7a and Fig. S4a, ESI†), i.e., only the first step of the mechanism occurs, which suggests that the carbon promotes the condensation reactions (the oxygen-containing surface groups may possess sufficient acidbase strengths to play a catalytic role in this process). It should be pointed out that titania nanoparticles can be prepared by reaction of titanium(IV) isopropoxide with benzyl alcohol when traditional heating is applied. ${ }^{45}$ The behavior observed when microwave heating is used may be explained by the higher microwave absorption ability of the carbon compared to the solvent: overheating of the carbon before reaching the temperature set-point could decrease considerably the induction period of the condensation reaction, leading to the formation of the $\mathrm{TiO}_{2}$ nanoparticles in short time, in opposition to what occurs in the absence of the carbon. Another possible explanation is based on the tendency of the titanium alkoxide molecules to interact with the carbon surface; specifically the Ti centers will tend to interact with the oxygen functionalities such as the carbonyl surface groups. This interaction can: (i) change the electron density at the Ti center and oxygen of the alkoxide ligand, facilitating a nucleophilic attack on the $\mathrm{Ti}$; (ii) cause instability of the ligands due to steric effects. Both effects could promote the condensation reactions.

\subsection{Xylose dehydration to furfural}

The prepared composite catalysts were tested in the reaction of xylose using a biphasic water-toluene solvent system (to avoid Fur loss reactions ${ }^{8,9,11,12}$ ) at $170{ }^{\circ} \mathrm{C}$. One of the critical requirements that solid acids must fulfil to be applied as catalysts in the aqueous phase reaction of saccharides to furanic aldehydes (e.g. Fur) is to be hydrothermally stable (e.g. towards disruption of metal/support interactions under the reaction conditions used). Hence, an initial evaluation of the hydrothermal stability of the as-prepared composite materials was carried out by subjecting them to hydrothermal treatment (HT) at $170{ }^{\circ} \mathrm{C}$ for $5 \mathrm{~h}$ (under similar conditions to those used in the catalytic tests, but without D-xylose). The $\mathrm{TiO}_{2} / \mathrm{RGO}$ and $\mathrm{TiO}_{2} / \mathrm{CB}$ gave the solids denoted $\mathrm{TiO}_{2} / \mathrm{RGO}-\mathrm{HT}$ and $\mathrm{TiO}_{2} / \mathrm{CB}-$ $\mathrm{HT}$, respectively, which were subsequently separated by filtration, dried at $55{ }^{\circ} \mathrm{C}$ overnight and characterized by several techniques, namely elemental analysis, powder XRD, TEM, TGA-DSC, Raman and FTIR spectroscopies (the results are shown in Fig. S5-S9 of the ESI†). A comparative analysis of the characterization results of the as-prepared and HT composites revealed that no significant structural or chemical changes occurred due to hydrothermal treatment. Titanium elemental analysis of the HT-treated solids indicated no metal oxide loss (less than $1 \%$ difference in the values of metal contents of the solids before and after HT, which is well within the experimental range of error). Furthermore, the corresponding solutions (denoted $\mathrm{Liq}-\mathrm{TiO}_{2} / \mathrm{RGO}$ and $\mathrm{Liq}-\mathrm{TiO}_{2} / \mathrm{CB}$ for $\mathrm{TiO}_{2} / \mathrm{RGO}$ and $\mathrm{TiO}_{2} / \mathrm{CB}$, respectively) did not contain measurable amounts of titanium, as determined by elemental analysis (detection limit: $0.1 \mu \mathrm{g}_{\mathrm{Ti}} \mathrm{L}^{-1}$ ). The absence of active species in the $\mathrm{Liq}^{-\mathrm{TiO}_{2}} / \mathrm{RGO}$ and $\mathrm{Liq}^{-\mathrm{TiO}_{2}} / \mathrm{CB}$ solutions was further confirmed by adding xylose to these solutions (0.67 $\mathrm{M}$ xylose) and leaving them to react at $170{ }^{\circ} \mathrm{C}$ during $2.5 \mathrm{~h}$; the Fur yields were $16 \%$ and $22 \%$ for $\mathrm{Liq}^{-\mathrm{TiO}_{2}} / \mathrm{RGO}$ and $\mathrm{Liq}-\mathrm{TiO}_{2} / \mathrm{CB}$, respectively. These results are similar to those obtained for the reaction of xylose without adding a catalyst, under similar reaction conditions, which gave $26 \%$ Fur yield, indicating that the solutions did not contain active species leached from the solids. Hence, both nanocomposite catalysts exhibit fairly good hydrothermal stability, particularly towards metal oxide leaching.

The reaction of xylose in the presence of $\mathrm{TiO}_{2} / \mathrm{RGO}$ or $\mathrm{TiO}_{2} /$ $\mathrm{CB}$ gave $c a$. $68 \%$ Fur yield at $3 \mathrm{~h}$ reaction (Fig. 8). In contrast, the reaction was sluggish when only the RGO or CB were used

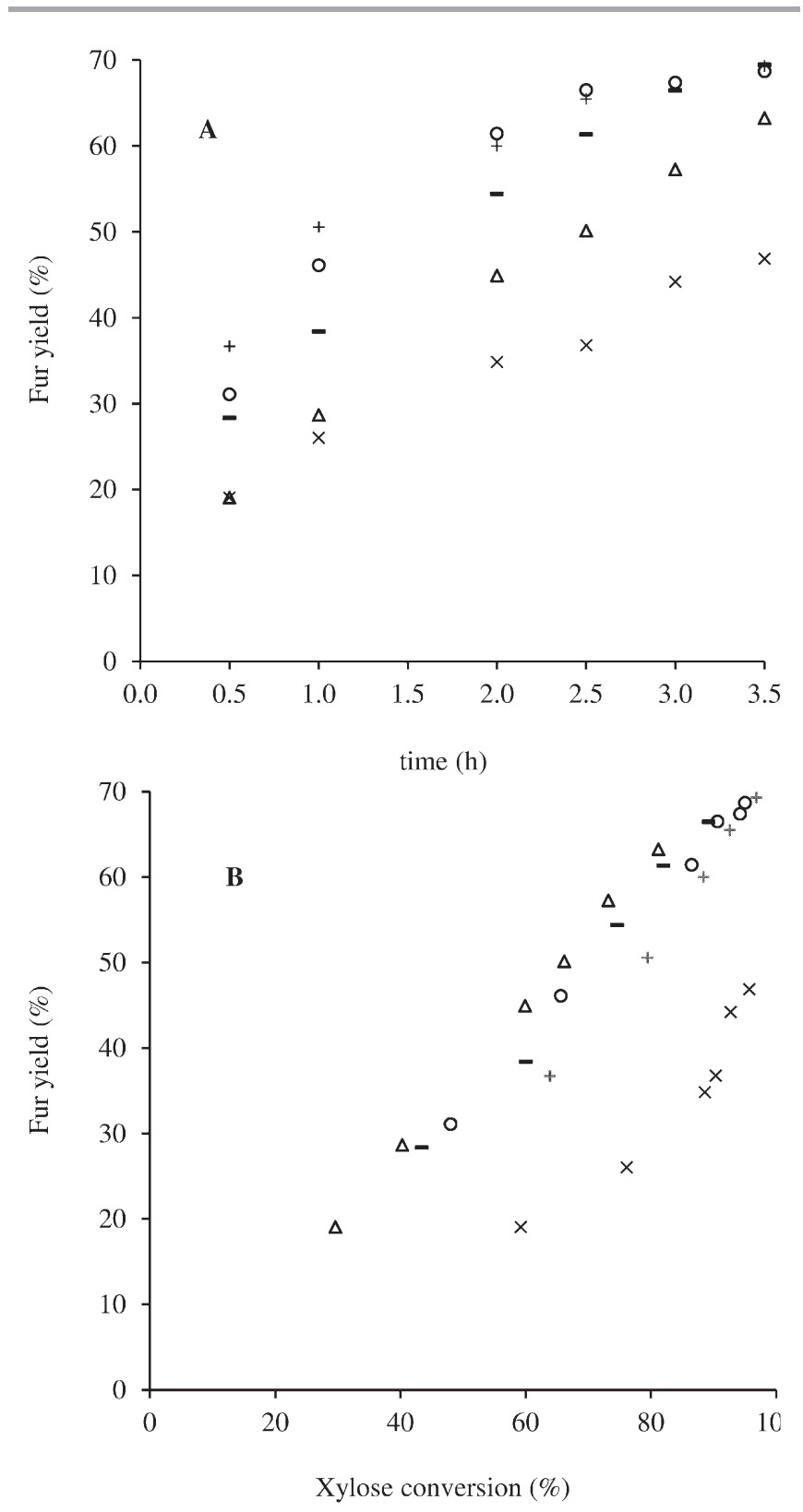

Fig. 8 Kinetic profiles of Fur formation (A) and dependence of Fur yields on xylose conversion (B), at $170{ }^{\circ} \mathrm{C}$, using a biphasic water-toluene solvent system (0.67 $\mathrm{M}$ xylose in the aqueous phase) and the catalyst $\mathrm{TiO}_{2} / \mathrm{CB}\left((+) 10 \mathrm{~g}_{\text {cat }} \mathrm{L}^{-1}\right.$; (-) $\left.5 \mathrm{~g}_{\text {cat }} \mathrm{L}^{-1} ;(\triangle) 2.5 \mathrm{~g}_{\text {cat }} \mathrm{L}^{-1}\right)$ or $\mathrm{TiO}_{2} / \mathrm{RGO}\left((\bigcirc) 10 \mathrm{~g}_{\text {cat }} \mathrm{L}^{-1}\right)$, or using solely water as solvent and the catalyst $\mathrm{TiO}_{2} / \mathrm{CB}\left((\times) 10 \mathrm{~g}_{\text {cat }} \mathrm{L}^{-1}\right)$. 
as catalysts under similar conditions (19\% and $24 \%$ yield, respectively). It is worth noting that the catalytic results are similarly poor for (i) the reaction without adding a catalyst, (ii) the reaction in the presence of the carbon supports (without $\mathrm{TiO}_{2}$ nanoparticles), and (iii) the $\mathrm{Liq}-\mathrm{TiO}_{2} / \mathrm{RGO}$ and $\mathrm{Liq}-\mathrm{TiO}_{2} /$ CB solutions discussed above. Hence, the supported $\mathrm{TiO}_{2}$ nanoparticles play an important catalytic role in promoting the dehydration of xylose into furfural. The catalytic performances of $\mathrm{TiO}_{2} / \mathrm{RGO}$ and $\mathrm{TiO}_{2} / \mathrm{CB}$ are comparable (Fig. 8), as the correspondent kinetic curves of Fur formation are roughly coincident and similarly high yields (67-69\%) are reached at high conversions (95-97\%). These results correlate well with the similar titanium contents and comparable textural properties of the two composites. Interestingly, the carbon support seems to have little influence on the catalytic activity of the materials. This means that RGO, which is produced from graphite by a harsh and time-consuming oxidation process, can be effectively replaced by cheaper CB without significantly affecting the Fur yields.

The stability of the catalysts was further investigated by performing consecutive $2.5 \mathrm{~h}$ batch runs; between each run the catalyst was separated from the reaction mixture by centrifugation, washed with water and methanol and dried overnight at $55{ }^{\circ} \mathrm{C}$. For the two catalysts, the Fur yields were similar throughout three runs (Fig. 9). The carbon content of the materials was measured after each run, and was found not to change significantly in relation to that of the pristine solids (44\%/47\%/46\% for $\mathrm{TiO}_{2} / \mathrm{RGO}$ and $52 \% / 52 \% / 53 \%$ for $\mathrm{TiO}_{2} / \mathrm{CB}$ after the batch runs $1 / 2 / 3$, respectively). Furthermore, the Raman, FTIR, TGA and DSC data confirmed the absence of coke on the used catalysts. The $I_{\mathrm{G}} / I_{\mathrm{D}}$ ratios remained unchanged, whereas it has been shown that accumulation of organic matter containing carbonyl groups on the surface of the catalysts causes this ratio to increase. ${ }^{22}$ Moreover, based on the literature data, coke deposits expectedly undergo exothermic decomposition above $200{ }^{\circ} \mathrm{C},{ }^{11,20}$ which was not observed in the TGA-DSC analyses of the composites

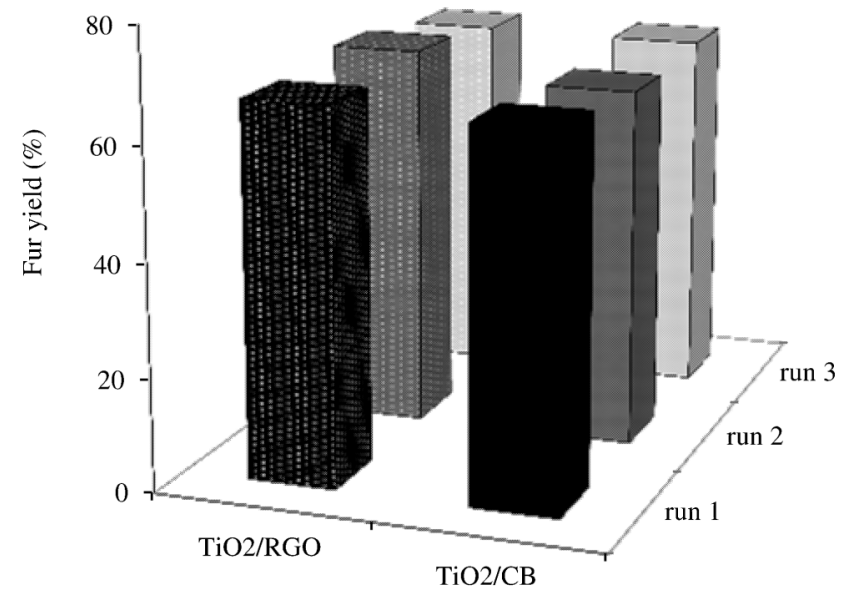

Fig. 9 Fur yield in recycling runs of the reaction of xylose in the presence of $\mathrm{TiO}_{2} / \mathrm{RGO}$ or $\mathrm{TiO}_{2} / \mathrm{CB}$, using the biphasic water-toluene solvent system. Reaction conditions: $0.67 \mathrm{M}$ xylose, $10 \mathrm{~g}_{\text {cat }} \mathrm{L}^{-1}$, water-toluene $(0.3: 0.7 \mathrm{v} / \mathrm{v})$, $170{ }^{\circ} \mathrm{C}, 2.5 \mathrm{~h}$. investigated in this work (Fig. S9 and S10, ESI $\dagger$ ). The powder XRD and TEM analyses of the used catalysts showed that no structural changes occurred during the catalytic reaction (Fig. 2 and 3, respectively), which is consistent with the catalysts' hydrothermal stabilities discussed above. These results show that the solids are fairly stable towards coking, which is an attractive property since costs associated with process interruptions and catalysts regeneration steps can be minimized. In contrast, for several types of solid acids described in the literature, tested in the same reaction under similar reaction conditions, it was reported that in order to remove coke and reactivate the catalysts (from the first batch run) it was necessary to apply thermal treatments in the range 250-550 ${ }^{\circ} \mathrm{C}$ (e.g. for micro/mesoporous aluminosilicates, ${ }^{8,11,13}$ silicoaluminophosphates, ${ }^{46}$ zirconium-tungsten mixed oxides $^{12}$ ) or chemical (oxidative) treatments (e.g. using $\mathrm{H}_{2} \mathrm{O}_{2}$ for sulfonic acid-functionalized mesoporous silicas). ${ }^{9,47}$

For comparison with the biphasic solvent system, the reaction of Xyl in the presence of $\mathrm{TiO}_{2} / \mathrm{CB}$ was carried out using solely water as solvent at $170{ }^{\circ} \mathrm{C}$ (the catalyst bulk density and total volume of reaction mixture were the same for the two sets of reaction conditions). The Fur yields at similar xylose conversions were lower for water (monophasic solvent system) than for the biphasic solvent system (Fig. 8); the former system led to $47 \%$ Fur yield at $94 \%$ conversion. These results are somewhat comparable to those reported previously for mesoporous (zirconium, aluminium)-tungsten mixed oxide $\left(47 \% \text { yield at } 93 \% \text { conversion, at } 170{ }^{\circ} \mathrm{C} / 8 \mathrm{~h}\right)^{12}$ and aluminosilicates (54-56\% yield at $91-97 \%$ conversion, at 170 $\left.{ }^{\circ} \mathrm{C} / 32 \mathrm{~h}\right)^{11}$ used in the same reaction under similar conditions. Nevertheless, $\mathrm{TiO}_{2} / \mathrm{CB}$ has the advantage of being far more active (similar results are obtained for a reaction time of $3.5 \mathrm{~h}$, using half the amount of loaded catalyst). In face of the high catalytic activity of the $\mathrm{TiO}_{2} / \mathrm{CB}$, its performance was further investigated by varying the amount of catalyst charged to the reactor (catalyst bulk density in the range $2.5-10 \mathrm{~g}_{\text {cat }} \mathrm{L}^{-1}$ ). Increasing the amount of catalyst tends to increase the rate of Fur formation and slightly higher Fur yields are reached at similar conversions (Fig. 8), which may be partly due to a more efficient in situ separation of Fur from the aqueous phase (avoiding consecutive reactions of Fur) when the reaction of xylose is slower. Nevertheless, the kinetic profiles of Fur formation tend to similar values after some hours: e.g. using a catalyst bulk density of $5 \mathrm{~g}_{\text {cat }} \mathrm{L}^{-1}$ the Fur yield at $3.5 \mathrm{~h}$ reaction was similar $(69 \%)$ to that obtained by using twice the amount of catalyst.

In Table 1 the performance of $\mathrm{TiO}_{2} / \mathrm{CB}$ in the dehydration of xylose into furfural is compared with that of other solid catalysts described in the literature, tested under batch conditions using a biphasic water-toluene solvent system. ${ }^{8-11,13,14,16,17,19,47,48}$ The $\mathrm{TiO}_{2} / \mathrm{CB}$ catalyst allows reaching relatively high Fur yields in short reaction times (e.g. in comparison to $\mathrm{H}_{2} \mathrm{Ti}_{3} \mathrm{O}_{7}$ nanosheets). ${ }^{20}$ This high catalytic activity may be partly due to a high density of accessible active sites provided by the supported layer of nanosized titania. Moreover, as discussed above, $\mathrm{TiO}_{2} / \mathrm{CB}$ is quite hydrothermally stable and fairly resistant to coke formation. Most of the heterogeneous catalysts tested in this reaction, on the other hand, are relatively easily deactivated by coke deposits that 
Table 2 Catalytic performance of different materials in the dehydration of xylose into furfural using a biphasic W-T solvent system

\begin{tabular}{|c|c|c|c|c|c|c|}
\hline Catalysts & $T /{ }^{\circ} \mathrm{C}^{a}$ & Time $/ \mathrm{h}^{b}$ & Xyl conv $/ \%{ }^{c}$ & Fur yield $/ \%^{d}$ & $\mathrm{Xyl} / \mathrm{cat}(\mathrm{w} / \mathrm{w})^{e}$ & Ref. \\
\hline $\mathrm{TiO}_{2} / \mathrm{CB}$ & 170 & 3.5 & 97 & 69 & $3-6$ & This work \\
\hline Zeolites H-Y, H-mordenite & 170 & 0.8 & $41-66$ & $34-42$ & 3.75 & 10 \\
\hline H-MCM-22, ITQ- $2^{g}$ & 170 & 16 & $\sim 99$ & $66-71$ & 1.5 & 11 \\
\hline H-beta ${ }^{g}$ & 170 & 4 & 98 & 54 & 1.5 & 8 \\
\hline H-beta/TUD-1 composite ${ }^{g}$ & 170 & 8 & 98 & 74 & 1.5 & 8 \\
\hline $\mathrm{H}_{2} \mathrm{Ti}_{3} \mathrm{O}_{7}$ nanosheets ${ }^{g}$ & 160 & 1 & $\sim 76$ & $\sim 40$ & 1.5 & 20 \\
\hline $\mathrm{Zr}(\mathrm{W}, \mathrm{Al})$ mixed oxides ${ }^{g}$ & 170 & 6 & 98 & 51 & 1.5 & 12 \\
\hline Bulk or MCM-41-supported (Per)Sulfated $\mathrm{ZrO}_{2}(\mathrm{Al})^{f, g}$ & 160 & 4 & $50-95$ & $27-46$ & 1.5 & 16 \\
\hline $\mathrm{SO}_{4}{ }^{2-} / \mathrm{ZrO}_{2}-\mathrm{Al}_{2} \mathrm{O}_{3} / \mathrm{SBA}-15^{f, g}$ & 160 & 4 & 99 & 53 & 1.5 & 14 \\
\hline $\mathrm{MCM}-41-\mathrm{SO}_{3} \mathrm{H}^{f, g}$ & 170 & 4 & 85 & 66 & 1.5 & 48 \\
\hline SBA-15- $\mathrm{SO}_{3} \mathrm{H}^{f, g}$ & 160 & 4 & 92 & 68 & 1.5 & 47 \\
\hline SBA-15- $\mathrm{SO}_{3} \mathrm{H}^{f, g}$ & 170 & 20 & 96 & 82 & 1.7 & 9 \\
\hline Poly(styrenesulphonic acid) & 170 & 2 & $\sim 63$ & $\sim 50$ & 3 & 17 \\
\hline $\mathrm{SO}_{4}^{2-} /\left(\mathrm{TiO}_{2} \text { or } \mathrm{SnO}_{2}\right)^{f, g}$ & 100 & 48 & $39-57$ & $17-27$ & 3 & 13 \\
\hline
\end{tabular}

${ }^{a}$ reaction temperature. ${ }^{b}$ reaction time. ${ }^{c}$ xylose conversion. ${ }^{d}$ furfural yield. ${ }^{e}$ weight ratio xylose/catalyst. ${ }^{f}$ refers to catalysts which suffered deactivation after the first batch run due to decomposition of the active sites. ${ }^{g}$ to catalysts which needed to be thermally and/or chemically treated prior to reuse.

passivate the catalyst surface (examples with the footnote $g$ in the first column of Table 2) and/or are chemically unstable (decomposition of the active species, e.g. via leaching; examples with the footnote $f$ in the first column of Table 2).

\section{Conclusions}

$\mathrm{TiO}_{2} / \mathrm{RGO}$ and $\mathrm{TiO}_{2} / \mathrm{CB}$ nanocomposite catalysts, formed by 8-9 $\mathrm{nm}$ anatase nanoparticles selectively grown on the carbons surfaces, were prepared by a simple and rapid microwaveassisted synthesis in benzyl alcohol. The materials were found to be promisingly active and hydrothermally stable for converting saccharides to furanic aldehydes. The reaction of xylose in the presence of $\mathrm{TiO}_{2} / \mathrm{RGO}$ or $\mathrm{TiO}_{2} / \mathrm{CB}$ gave similarly high furfural yields ( $c a .67-69 \%)$ after $3 \mathrm{~h}$ of reaction, indicating that RGO can be effectively replaced by relatively cheap CB without significantly affecting the Fur yields. The catalytic activity is associated with the supported $\mathrm{TiO}_{2}$ nanoparticles. These catalysts were found to be very stable, especially towards leaching of the active species under hydrothermal conditions and coke formation in comparison with several other solid catalysts reported in the literature, tested in the same reaction..$^{8,9,10,12}$ The two composites were effectively reused after a simple wash and drying procedure without decrease in Fur yields being observed during at least three batch runs (64$68 \%$ Fur yield). Catalytic nanomaterials with interesting performances may be prepared using this synthetic approach since it is very versatile, allowing the synthesis of a high variety of metal oxides, hybrid materials and composites (using different supports), as single or multifunctional catalysts (important for process intensification).

\section{Acknowledgements}

We are grateful to the Fundação para a Ciência e a Tecnologia(FCT), the Programa Operacional Ciência e
Inovação (POCI) 2010, Orçamento do Estado (OE), Fundo Europeu de Desenvolvimento Regional (FEDER) for general funding (projects POCTI/QUI/56112/2004, PTDC/CTM/098361/ 2008), and to CICECO (Pest-C/CTM/LA0011/2011). Regina Rothe (Max Planck Institute of Colloids and Interfaces) is acknowledged for the nitrogen adsorption measurements, A.J.S. Fernandes (University of Aveiro) for the Raman measurements and Dr F. Domingues (University of Aveiro) for access to HPLC equipment. We acknowledge the FCT for post-doctoral grants to P.R. (SFRH/BPD/79910/2011) and S.L. (SRFH/BPD/ 23765/2005).

\section{Notes and references}

1 R. Karinen, K. Vilonen and M. Niemelä, ChemSusChem, 2011, 4, 1002.

2 M. J. Climent, A. Corma and S. Iborra, Green Chem., 2011, 13, 520 .

3 G. W. Huber, J. N. Chheda, C. J. Barrett and J. A. Dumesic, Science, 2005, 308, 1446.

4 R. Xing, W. Qi and G. W. Huber, Energy Environ. Sci., 2011, 4, 2193.

5 R. Xing, A. V. Subrahmanyam, H. Olcay, W. Qi, G. P. van Walsum, H. Pendse and G. W. Huber, Green Chem., 2010, 12, 1933.

6 O. O. James, S. Maity, L. A. Usman, K. O. Ajanaku, O. O. Ajani, T. O. Siyanbola, S. Sahu and R. Chaubey, Energy Environ. Sci., 2010, 3, 1833.

7 Y. C. Kim and H. S. Lee, J. Ind. Eng. Chem., 2001, 7, 424.

8 S. Lima, M. M. Antunes, A. Fernandes, M. Pillinger, M. F. Ribeiro and A. A. Valente, Appl. Catal., A, 2010, 388, 141.

9 I. Agirrezabal-Telleria, J. Requies, M. B. Güemez and P. L. Arias, Appl. Catal. B, 2012, 115-116, 169.

10 C. Moreau, R. Durand, D. Peyron, J. Duhamet and P. Rivalier, Ind. Crops Prod., 1998, 7, 95.

11 M. M. Antunes, S. Lima, A. Fernandes, M. Pillinger, M. F. Ribeiro and A. A. Valente, Appl. Catal. A, 2012, 417-418, 243. 
12 M. M. Antunes, S. Lima, A. Fernandes, J. Candeias, M. Pillinger, S. M. Rocha, M. F. Ribeiro and A. A. Valente, Catal. Today, 2012, 195, 127-135.

13 S. Lima, M. Pillinger and A. A. Valente, Catal. Commun., 2008, 9, 2144.

14 T. Suzuki, T. Yokoi, R. Otomo, J. N. Kondo and T. Tatsumi, Appl. Catal., A, 2011, 408, 117.

15 X. Shi, Y. Wu, P. Li, H. Yi, M. Yang and G. Wang, Carbohydr. Res., 2011, 346, 480.

16 A. S. Dias, S. Lima, M. Pillinger and A. A. Valente, Catal. Lett., 2007, 114, 151.

17 E. Lam, E. Majid, A. C. W. Leung, J. H. Chong, K. A. Mahmoud and J. H. T. Luong, ChemSusChem, 2011, 4, 535.

18 M. L. Granados, A. C. Alba-Rubio, I. Sadaba, R. Mariscal, I. Mateos-Aparicio and A. Heras, Green Chem., 2011, 13, 3203.

19 A. S. Dias, M. Pillinger and A. A. Valente, Microporous Mesoporous Mater., 2006, 94, 214.

20 A. S. Dias, S. Lima, D. Carriazo, V. Rives, M. Pillinger and A. A. Valente, J. Catal., 2006, 244, 230.

21 M. Toda, A. Takagaki, M. Okamura, J. N. Kondo, S. Hayashi, K. Domen and M. Hara, Nature, 2005, 438, 178.

22 E. Lam, J. H. Chong, E. Majid, Y. Liu, S. Hrapovic, A. C. W. Leung and J. H. T. Luong, Carbon, 2012, 50, 1033.

23 W. Daengprasert, P. Boonnoun, N. Laosiripojana, M. Goto and A. Shotipruk, Ind. Eng. Chem. Res., 2011, 50, 7903.

24 H. D. Mansilla, J. Baeza, S. Urzúa, G. Maturana, J. Villaseñor and N. Durán, Bioresour. Technol., 1998, 66, 189.

25 A. Chareonlimkun, V. Champreda, A. Shotipruk and N. Laosiripojana, Bioresour. Technol., 2010, 101, 4179.

26 S. Dutta, S. De, A. K. Patra, M. Sasidharan, A. Bhaumik and B. Saha, Appl. Catal. A, 2011, 409-410, 133.

27 S. De, S. Dutta, A. K. Patra, A. Bhaumik and B. Saha, J. Mater. Chem., 2011, 21, 17505.

28 S.T. Sie, Appl. Catal., A, 2001, 212, 129.

29 N. Pinna, S. Grancharov, P. Beato, P. Bonville, M. Antonietti and M. Niederberger, Chem. Mater., 2005, 17, 3044.
30 N. Pinna, G. Neri, M. Antonietti and M. Niederberger, Angew. Chem., Int. Ed., 2004, 43, 4345.

31 N. Pinna, G. Garnweitner, M. Antonietti and M. Niederberger, Adv. Mater., 2004, 16, 2196.

32 N. Pinna, J. Mater. Chem., 2007, 17, 2769.

33 S. Baek, S.-H. Yu, S.-K. Park, A. Pucci, C. Marichy, D.-C. Lee, Y.-E. Sung, Y. Piao and N. Pinna, RSC Adv., 2011, 1, 1687.

34 P. A. Russo, N. Donato, S. G. Leonardi, S. Baek, D. E. Conte, G. Neri and N. Pinna, Angew. Chem., Int. Ed., 2012, 51, 11053.

35 I. Bilecka, I. Djerdj and M. Niederberger, Chem. Commun., 2008, 886.

36 I. Bilecka, L. Luo, I. Djerdj, M. D. Rossell, M. Jagodič, Z. Jagličić, Y. Masubuchi, S. Kikkawa and M. Niederberger, J. Phys. Chem. C, 2011, 115, 1484.

37 W. S. Hummers and R. E. Offeman, J. Am. Chem. Soc., 1958, 80, 1339.

38 T. Ohsaka, F. Izumi and Y. Fujiki, J. Raman Spectrosc., 1978, 7, 321.

39 K. N. Kudin, B. Ozbas, H. C. Schniepp, R. K. Prud'homme, I. A. Aksay and R. Car, Nano Lett., 2007, 8, 36.

40 P. J. M. Carrott, R. A. Roberts and K. S. W. Sing, Carbon, 1987, 25, 769.

41 W. Chen, L. Yan and P. R. Bangal, Carbon, 2010, 48, 1146.

42 N. Lakshmi, N. Rajalakshmi and K. S. Dhathathreyan, J. Phys. D: Appl. Phys., 2006, 39, 2785.

43 A. M. Peiró, J. Peral, C. Domingo, X. Domènech and J. A. Ayllón, Chem. Mater., 2001, 13, 2567.

44 A. Vioux, Chem. Mater., 1997, 9, 2292.

45 M. Niederberger and N. Pinna, Metal Oxide Nanoparticles in Organic Solvents. Synthesis, Formation, Assembly and Application, Springer-Verlag, London, 2009.

46 S. Lima, A. Fernandes, M. M. Antunes, M. Pillinger, F. Ribeiro and A. A. Valente, Catal. Lett., 2010, 135, 41.

47 X. Shi, Y. Wu, H. Yi, G. Rui, P. Li, M. Yang and G. Wang, Energies, 2011, 4, 669.

48 A. S. Dias, M. Pillinger and A. A. Valente, J. Catal., 2005, 229, 414 